\title{
Effect of Megasphaera elsdenii NCIMB 41125 dosing on rumen development, volatile fatty acid production and blood $\beta$-hydroxybutyrate in neonatal dairy calves
}

\author{
M. C. Muya ${ }^{1 \#}$, F.V. Nherera ${ }^{1}$, K. A. Miller ${ }^{2}$, C. C. Aperce $^{2}$, P. M. Moshidi ${ }^{1}$ and L. J. Erasmus ${ }^{3}$ \\ ${ }^{1}$ Agricultural Research Council-API, Private Bag X2, Irene 0062, South Africa, \\ ${ }^{2}$ MS Biotec, Wamego, KS 66547, United State, and \\ ${ }^{3}$ Department of Animal and Wildlife Sciences, University of Pretoria, Pretoria 001, South Africa \\ ${ }^{\#}$ Correspondence: M.C. Muya, Agricultural Research Council, Animal Production Institute, Ruminant Nutrition, \\ Private Box X2, Irene, 0062, Pretoria, South Africa. Tel.: +27 012 6729122; Fax: +27 012665 1603; E-mail: \\ MuyaM@arc.agric.za
}

\section{Abstract}

Thirty calves were randomly assigned to 2 treatments and fed until weaning (42 days (d) of age). Treatments were a control group $(\mathrm{n}=15)$, which did not receive Megasphaera elsdenii $(\mathrm{Me} 0)$ and a $M$. elsdenii group, which received a 50-mL oral dose of M. elsdenii NCIMB $41125\left(10^{8}\right.$ $\mathrm{CFU} / \mathrm{mL}$ ) at $\mathrm{d} 14 \mathrm{~d}$ of age (Me14). Calves were given colostrum for the first $3 \mathrm{~d}$ followed by limited whole milk feeding. A commercial calf starter was offered ad libitum starting at d 4 until the end of the study. Fresh water was available throughout the study. Feed intake and growth were measured. Blood samples were collected via jugular venipuncture to determine $\beta$ hydroxybutyrate (BHBA) concentrations. Fourteen male calves (7 per group) were euthanized on d 42 and digestive tracts harvested. Reticulo-rumen weight was determined and rumen tissue samples collected from the cranial and caudal sacs of the ventral and dorsal portions of the 
rumen for measurements of papillae length, papillae width, and rumen wall thickness. Dosing with M. elsdenii NCIMB 41125 improved starter dry matter intake (DMI), weaning body weight (BW), and tended to improve average daily gain. Calves in Me14 group had greater plasma BHBA concentration than Me0-calves during the last 3 weeks of the trial, and had at $\mathrm{d} 42$ greater reticulo-rumen weight, papillae width and papillae density compared to Me0. No differences in rumen wall thickness or papillae length were observed between the two groups. Total volatile fatty acids, acetate, and propionate production did not differ between treatments, but butyrate production was greater in Me14 than Me0. Dosing M. elsdenii NCIMB 41125 showed benefit for calves with improved feed intake and rumen development suggesting increased epithelium metabolism and improved absorption of digestive end products.

Keywords: Megasphaera elsdenii, $\beta$-hydroxybutyrate, rumen development, neonatal calves, starter intake, weaning

\section{Introduction}

Many dairy producers wean their calves from whole milk or milk replacer early (3 to 6 weeks). Rapid rumen development is therefore critical before weaning as it influences post weaning intake of solid feed, growth rates and health (Baldwin et al., 2004; Greenwood et al., 1997). Rumen development is dependent on intake of solid feed (Lesmeister and Heinrichs, 2004), which is fermented to volatile fatty acids (VFA's) that stimulate rumen papillae development in calves (Sander et al., 1959). Starter feeds that promote production of butyrate are the preferred feed type for triggering papillae growth in the rumen (Stobo et al., 1966). Amongst VFA's, 
Butyrate has the greatest effects on ruminal epithelium. Butyrate is reported to increases blood flow during nutrients absorption and metabolism and directly affect ruminal epithelium gene expression (Baldwin et al., 2004).

Megasphaera elsdenii, a lactate-utilising bacteria, plays a major role in production of branchedchain VFA's in the rumen (Wallace 1986). This bacteria converts lactic acid to propionate and butyrate and converts glucose to butyrate (Marounek et al., 1989; Henning et al., 2010). The potential of M. elsdenii to increase molar proportions of ruminal propionate and/or butyrate was reported (Marounek et al., 1989; Aikman, 2008; Aikman et al., 2009; Henning et al., 2010) and the role of these two VFA's in stimulating rumen epithelial cells and papillae development, increasing the capacity of solid feed intake were reviewed (Warner et al., 1956; Tamate et al., 1962; Lane and Jesse, 1997; Coverdale et al., 2004). Butyrate provides energy for thickening of the rumen wall, formation of papillae, and increasing capillary development (Weigand et al., 1975). In young calves, the physical development of the rumen is associated with changes in blood $\beta$-hydoxybutyrate (BHBA) produced from butyrate as a result of ruminal fermentation of carbohydrate (Quigley et al., 1991). Dosing calves with M. elsdenii may increase production of butyrate and accelerate rumen development during the neonatal phase. The objectives of this experiment were to determine the effects of dosing calves with M. elsdenii NCIMB 41125 on solid feed intake, growth, serum BHBA and rumen development (Figs 1-3). 


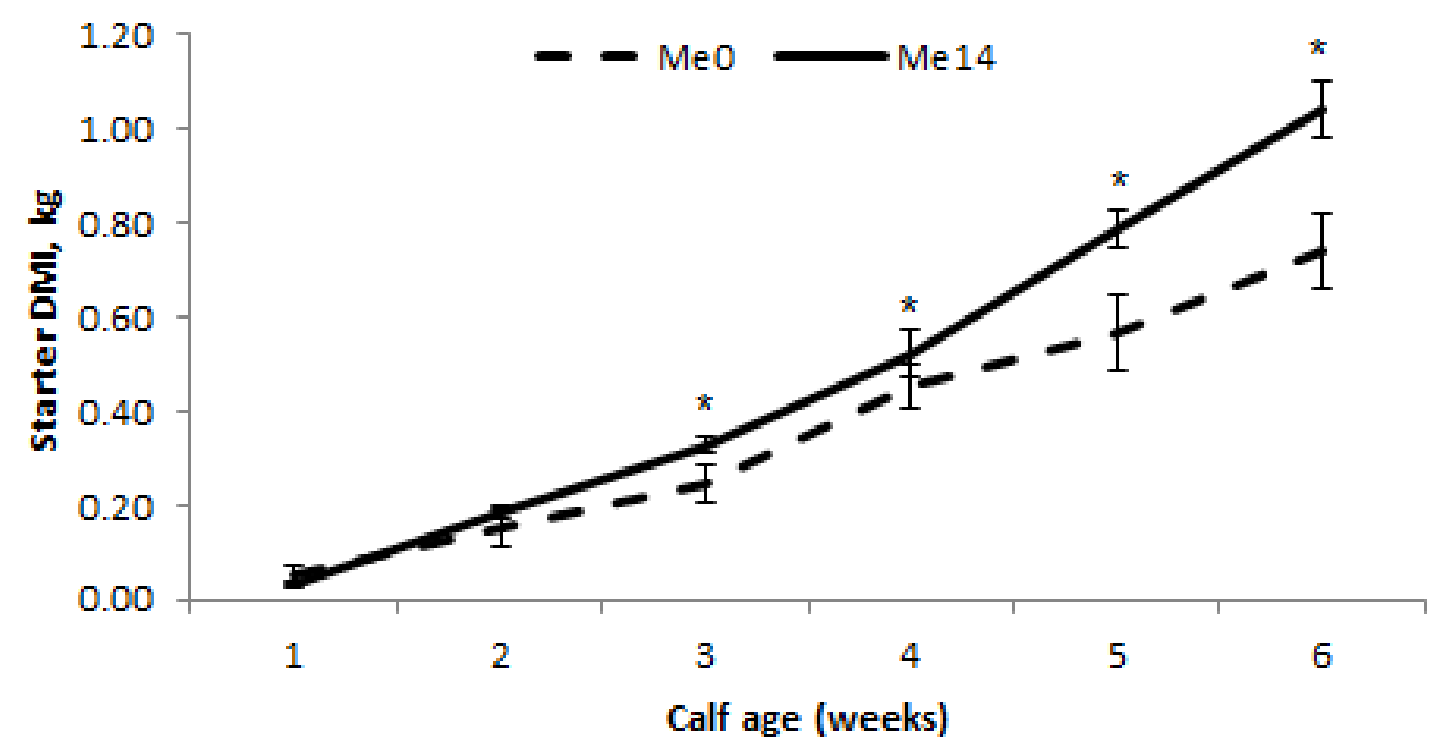

Figure 1. Starter dry matter intake for calves with (Me14) or without (Me0) M. elsdenii NCIMB 41125 at $14 \mathrm{~d}$ of age

*: Significant difference between groups $(P=0.05)$

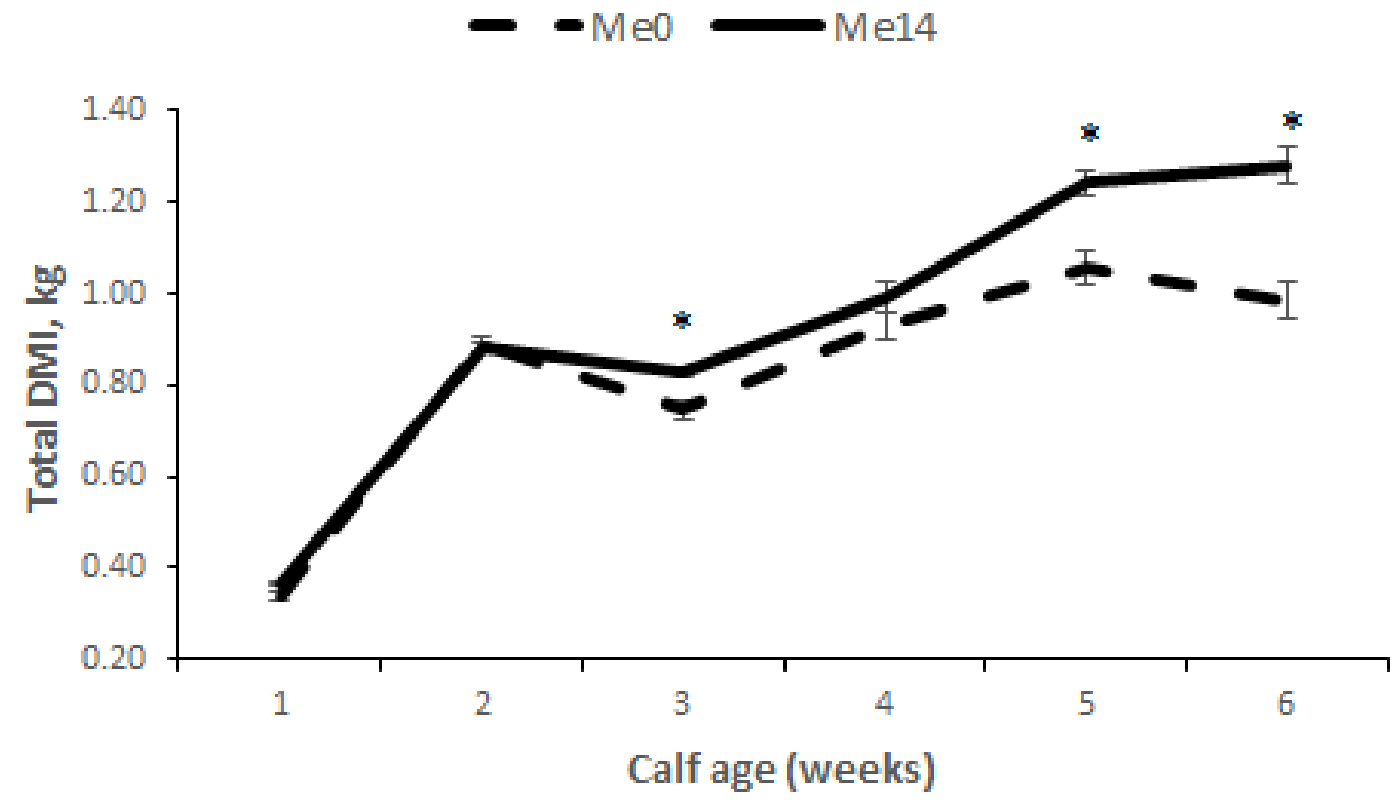

Figure 2. Total dry matter intake for calves with (Me14) or without (Me0) M. elsdenii NCIMB 41125 at 14 d of age *: Significant difference between groups $(P=0.05)$ 


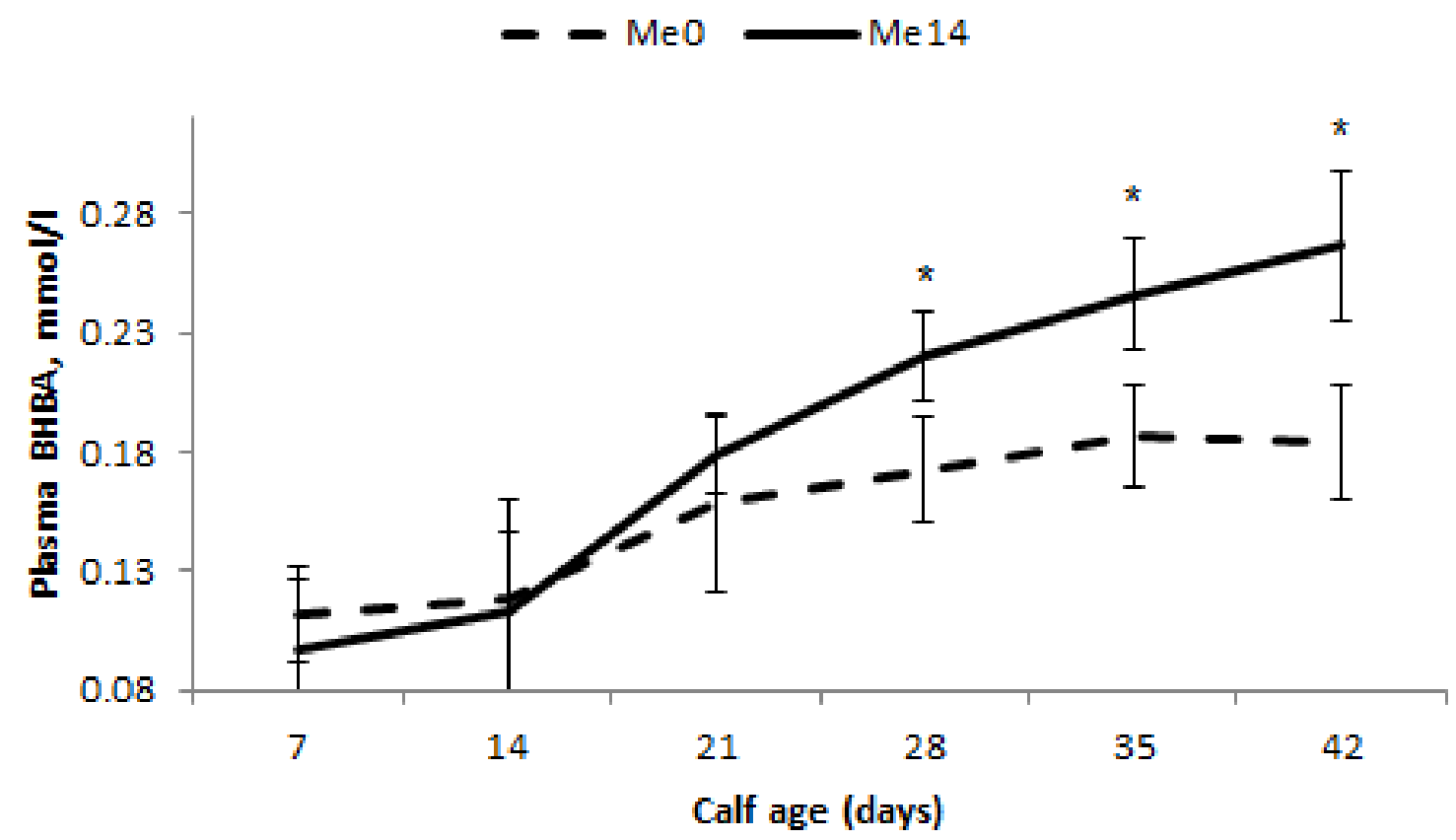

Figure 3. Plasma $\beta$-hydroxybutyrate (BHBA) of calves with (Me14) or without (Me0) M. elsdenii NCIMB 41125 at $14 \mathrm{~d}$ of age

*: Significant difference between groups $(P=0.05)$

\section{Materials and methods}

\section{Animal and diets}

The experimental protocol and procedures were approved by the Animal Ethics Committee (APIEC11/028) of the Agricultural Research Council at Irene, Pretoria, South Africa.

Thirty healthy male and female Holstein calves $(34.6 \pm 5.04)$ from the Agricultural Research Council/ Animal Production Institute in Pretoria (South Africa) were randomly allocated postpartum to two treatment groups (males $(n=7)$, females $(n=8)$ per treatment): Control group (Me0), which did not receive Megasphaera elsdenii (M. elsdenii) NCIMB 41125 and (Me14), which received a 50-mL $\left(10^{8} \mathrm{CFU} / \mathrm{mL}\right)$ oral dose of $M$. elsdenii NCIMB 41125 at $14 \mathrm{~d}$ of age. All bull calves were euthanised on d 42 using captive bolt stunning and exsanguination for rumen evaluation. The product containing $M$. elsdenii NCIMB 41125 is commercially available 
as Megamilk, supplied by Afrivet, Office Park, 195 Dawie Str, Silver Lakes Road, Hazeldean 0081, South Africa. Calves were given colostrum for the first 3 days of life before receiving cow's milk as shown in Table 1 . A commercial calf starter feed (18.9 \% CP, $3.9 \%$ fat) was offered ad libitum starting at d 4 of age until weaning at d 42 . Fresh water was available throughout the study.

Table 1. Milk feeding regime

\begin{tabular}{llll}
\hline & & Morning & Afternoon \\
\hline Day 4 to day 7 & Milk & $2 \mathrm{~L}$ & $2 \mathrm{~L}$ \\
\hline Day 8 to day 14 & Milk & $3 \mathrm{~L}$ & $3 \mathrm{~L}$ \\
\hline Day 15 to day 35 & Milk & $2 \mathrm{~L}$ & $2 \mathrm{~L}$ \\
\hline From Day 36 to weaning (day 42) & Milk & $4 \mathrm{~L}$ & - \\
\hline
\end{tabular}

\section{Measurements and analysis}

Consumption of starter, milk and water by each calf were recorded daily throughout the experiment to estimate intake. Calves were initially offered $250 \mathrm{~g}$ of starter, and remaining feed was weighed at each delivery time the next day. Daily starter feed offerings were increased in $250 \mathrm{~g}$ increments when calves refused less than $50 \mathrm{~g}$ of feed. The DM contents of the starter was determined by oven drying at $60^{\circ} \mathrm{C}$ for $48 \mathrm{~h}$ and milk DM was determined by freeze-drying. Calves were weighed at birth and at 7 day intervals throughout the experiment and the average weigh gain (ADG) was determined weekly. Weighing was done before morning milk and starter feeding. Jugular blood was collected from all male calves at 7, 14, 21, 28, 35 and $42 \mathrm{~d}$ of age in the morning 1 hour post-feeding by venipuncture for determination of BHBA. Blood was collected into $10 \mathrm{~mL}$ collection tubes containing sodium heparin. Two $\mathrm{mL}$ of blood were then transferred to two clean test tubes. Cold $30 \%$ perchloric acid was added in a 1:1 ratio to the 
blood samples, for the precipitation of protein. After thorough mixing, the precipitated protein was removed by centrifuging in a refrigerated centrifuge (RCF: 1500) for $20 \mathrm{~min}$. The clear supernatant was quickly transferred to clean glass tubes and recapped with clean screw caps, to prevent evaporation of acetone, and stored at $-20^{\circ} \mathrm{C}$, until analyses for BHBA. The determination of BHBA was carried out by means of enzymatic analysis (Williamson et al., 1962).

After euthanised, Digestive tracts were harvested, emptied, and rinsed with cold water. Rumen tissue samples were collected from the cranial and caudal sacs of the ventral and dorsal portions of the rumen $($ area $n=4)$. Three random tissue samples were collected from each area (sample $n$ = 12). Measurements for papillae length, papillae width, and rumen wall thikness were performed in duplicate according to Lesmeister et al. (2004).

\section{Statistical analysis}

Average daily gain, starter and total DMI, and plasma BHBA were analyzed as repeated measures using the PROC MIXED statement of SAS (SAS Institute, 2009). Parameters measured daily were pooled by week for analysis. The statistical model included calf as a random effect, and treatment group and its interaction with time as a fixed effect. A significant effect of treatment by week was observed for DMI and BHBA, so each week of these data was analyzed separately. The model was subjected to an autoregressive order one. Significance was declared at $\mathrm{p}<0.05$ and tendencies were accepted if $0.05<\mathrm{p}<0.10$. Differences between treatment means across time were assessed with a multiple test comparison using the Tukey's test. 
The statistical model used for repeated measure analyses was

$Y_{c i t}=\mu+\alpha_{i}+\beta_{t}+\mathrm{T}_{i t}+\delta_{c i}+e_{c i t}$,

where $Y_{c i t}=$ an observation value for ADG, starter DMI, total DMI and plasma BHBA measured from calf $c$ from treatment $\mathrm{i}$ at time $t$;

$\mu=$ overall mean for the population;

$\alpha_{i}=$ fixed effect of treatment $\mathrm{i}$, where $\mathrm{i}=\mathrm{Me} 0$ or Me14;

$\beta_{t}=$ fixed effect of time $t$, where $t=\mathrm{w} 1,2,3,4,5$ or 6 for starter DMI, total DMI, ADG and BHBA;

$\mathrm{T}_{i t}=$ fixed interaction of effect of treatment $\mathrm{i}$ and time $t$;

$\delta_{c i}=$ random effect of calf $c$ nested within i treatment; and

$e_{c i t}=$ error associated with the measurement taken from calf $c$ from group $g$ at time $t$.

Means for gain:feed, initial and weaning BW, reticulo-rumen, papillae length, papillae width, and rumen wall thikness, were subjected to ANOVA using PROC GLM (SAS Institute, 2009). Significance was declared at $\mathrm{p}<0.05$ and tendencies were accepted if $0.05<\mathrm{p}<0.10$. The statistical model used was

$Y_{c i}=\mu+T_{i}+\delta_{c}+e_{c i}$

Where $\mathrm{Y}_{c i}=$ observation value taken from calf $c$ at $t$ time.

$\mu=$ overall mean of the population,

$\mathrm{T}_{i}=$ fixed effect of the $\mathrm{i}^{\text {th }}$ treatment (Me0 or M14), 
$\delta c=$ random effect of calf, and

$\mathrm{e}_{c i}=$ error associated with the measurement taken from calf $c$ from $\mathrm{i}^{\text {th }}$ treatment

\section{Results}

Intake and body weight Gain

There were effects $(\mathrm{p}<0.001)$ of treatment, week and their interaction for starter and total DMI

(Table 1). Calves in Me14 group consumed 29.7 and $13.2 \%$ more starter feed and total dry matter (milk + starter), respectively, than Me0 calves $(\mathrm{p}<0.05)$, but gain numerically $17 \%$ more $\mathrm{kg} / \mathrm{d}$ weight than Me0. Weaning BW, was also higher on Me14 compared to $\mathrm{Me} 0(\mathrm{p}=0.03)$. The gain:feed ratio was not different between treatments but ADG tended $(p=0.10)$ to be greater for Me14 calves.

Plasma BHBA did not differ $(\mathrm{p}>0.05)$ between Me0 and Me14 groups from $\mathrm{d} 7$ to $\mathrm{d} 21$ averaging $0.10,0.12$ and $0.17 \mathrm{mmol} / \mathrm{L}$, respectively. From d 28 to d 42, plasma BHBA of Me14 calves were higher than $\mathrm{Me} 0(\mathrm{p}=0.003)$.

Table 2. Least square means for performance and BHBA of calves with (Me14) or without (Me0) M. elsdenii NCIMB 41125 at $14 \mathrm{~d}$ of age.

\begin{tabular}{|c|c|c|c|c|c|c|}
\hline \multirow{2}{*}{ Items } & \multicolumn{2}{|c|}{ Treatments } & \multirow{2}{*}{ SEM } & \multicolumn{3}{|c|}{$\mathrm{p}$-value } \\
\hline & $\mathrm{MeO}$ & Me14 & & $\mathrm{T}$ & Time & T x Time \\
\hline \multicolumn{7}{|l|}{$\mathrm{BW}, \mathrm{kg}$} \\
\hline Initial & 33.4 & 35.8 & 1.7 & 0.18 & - & - \\
\hline Weaning & 50.5 & 55.8 & 2.2 & 0.03 & - & - \\
\hline $\mathrm{ADG}, \mathrm{kg} / \mathrm{d}$ & 0.41 & 0.48 & 0.05 & 0.10 & 0.018 & 0.20 \\
\hline Starter DMI, kg/d & 0.37 & 0.48 & 0.01 & $<0.001$ & $<0.001$ & $<0.001$ \\
\hline Total DMI, kg/d & 0.83 & 0.94 & 0.01 & $<0.001$ & $<0.001$ & $<0.001$ \\
\hline Gain: Feed & 1.07 & 1.02 & 0.14 & 0.68 & - & - \\
\hline Plasma BHBA, mmol/1 & 0.17 & 0.22 & 0.01 & $<0.003$ & $<0.001$ & 0.23 \\
\hline
\end{tabular}

Values in the same row differ if $\mathrm{P} \leq 0.05$ and tend to differ if $0.05 \geq \mathrm{p} \leq 0.10$

Gain: Feed: Calculated as Final Body weight - Initial body weight / Starter DMI

T: Treatment; SEM: Standard error of mean 
Least square means of total and individual VFA concentrations are presented in Table 2. Total VFA $(96.7 \pm 5.6 \mu \mathrm{mol} / \mathrm{L})$, acetate $(53.7 \pm 3.9 \mu \mathrm{mol} / \mathrm{L})$ and propionate $(24.2 \pm 1.2 \mu \mathrm{mol} / \mathrm{L}) \mathrm{did}$ not differ between treatments $(\mathrm{p}>0.10)$, but butyrate concentration was greater in Me14 than $\operatorname{Me} 0(p=0.04)$. Calves in Me14 treatment had greater reticulo-rumen weight $(\mathrm{p}=0.01)$ and papillae density $(\mathrm{p}=0.02)$, with greater papillae width $(\mathrm{p}<0.01)$ compared to Me0. No differences in rumen wall thickness $(1.58 \pm 0.1 \mathrm{~cm})$ and papillae length $(1.48 \pm 0.1 \mathrm{~cm})$ were observed between the two groups $(\mathrm{p}>0.10)$.

\section{Discussion}

Greater solid feed intake is very important in early weaning management systems because it determines growth rates and calf health post weaning (Greenwood et al., 1997). In neonatal calves, solid feed intake is conditioned by rumen (Kristensen et al., 2007), which affects digestion and absorption of nutrients (Gorka et al., 2011). Dosing M. elsdenii NCIMB 41125 stimulated feed intake in agreement with Miller et al. (2013), leading to Me14 calves consuming more starter than $\mathrm{Me} 0$ calves, suggesting a more developed absorptive capacity (Coverdale et al., 2004). Administering M. elsdenii NCIMB 41125 improved growth of the calves, as they gained $17 \%$ more $\mathrm{kg} / \mathrm{d}$ and were $5.3 \mathrm{~kg}$ heavier than $\mathrm{Me} 0$ at weaning. This can be attributed to increased nutrient digestibility due to early increased starter DMI (Anderson et al., 1987; Terre et al., 2007), and consequently improved ruminal fermentation activities in Me14 treatment. Increased feed intake was previously reported when lambs (Henning et al., 2009) and steers (Henning et al., 2010) were drenched with M. elsdenii NCIMB 41125. Increasing in DMI detected in this study is similar to that of Drouillard (2004), who found that cattle drenched with strain 41125 
tended to maintain higher intakes throughout the experiment than control cattle. In contrast no difference in feed intake was observed by Leeuw et al. (2009) with the same strain of M. elsdenii on feedlot steer fed high and low roughage diets, but ADG was improved from week 3 after dosing. (Table 3)

Table 3. Least square means for measurements taken at 42 days of age of calves with (Me14) or without (Me0) $M$. elsdenii NCIMB 41125 at $14 \mathrm{~d}$ of age

\begin{tabular}{|c|c|c|c|c|}
\hline \multirow{2}{*}{ Items } & \multicolumn{2}{|c|}{ Treatments } & \multirow{2}{*}{ SEM } & \multirow{2}{*}{ p-value } \\
\hline & Me0 & Me14 & & \\
\hline \multicolumn{5}{|c|}{ Ruminal volatile fatty acid production, $\mu \mathrm{mol} / \mathrm{L}$} \\
\hline Total VFA & 96.2 & 97.2 & 8.681 & 0.882 \\
\hline Acetate & 53.8 & 53.6 & 3.883 & 0.962 \\
\hline Butyrate & 10.7 & 15.9 & 1.279 & 0.037 \\
\hline Propionate & 24.3 & 24.1 & 1.175 & 0.915 \\
\hline \multicolumn{5}{|l|}{ Rumen development } \\
\hline Reticulo-rumen, $\mathrm{kg}$ & 1.05 & 1.17 & 0.0246 & 0.010 \\
\hline Rumen wall thickness, $\mathrm{cm}$ & 1.60 & 1.56 & 0.102 & 0.826 \\
\hline Papillae length, cm & 1.34 & 1.62 & 0.105 & 0.182 \\
\hline Papillae width, $\mathrm{cm}$ & 0.86 & 1.17 & 0.027 & $<0.001$ \\
\hline Papillae density, number/cm2 & 87.1 & 97.6 & 2.343 & 0.023 \\
\hline
\end{tabular}

Plasma BHBA concentration and its precursor rumen butyrate were found greater in Me14. The increased blood BHBA production from butyrate by rumen epithelial cells increased as age increases in both groups of calves (Me0 and Me14) as also reported by Giesecke et al. (1979) and Bush (1988), but was more pronounced for Me14 calves than for Me0 and can be associated with the greater starter intake by Me14 calves. Higher butyrate production could have increased ketogenesis in the rumen (Quigley et al., 1991) leading to greater plasma BHBA. Rumen butyrate is oxidized by the rumen epithelial cells as it passes through the rumen wall (Quigley, 1991; Lesmeister and Heinrichs, 2004). Dosed calves had heavier reticulorumen and more dense and longer papillae. These results indicate that dosing M. elsdenii NCIMB 41125 stimulated rumen butyrate and plasma BHBA production, and resulted in a faster rumen function 
development, suggesting more energy for thickening of the rumen wall, formation of papillae, and increasing capillary development (Weigand et al., 1975).

The association of rumen epithelial cell proliferation with increased plasma butyric acid was previously reported with dietary supplementation (Gorka et al., 2011) and with infusions (Mentschel et al., 2001) of sodium salt of butyrate to dairy calves. These reports suggested that the greatest effect on rumen papillae development was due to high rates of butyric acid metabolism in mucosa cells. Reticulum weight increases with increased BW (Tamate et al., 1962). Gorka et al. (2011) observed that dietary supplementation with butyric acid increased reticulorumen weight and papillae length and width in dairy calves fed limited amount of milk (10\% BW) . Dosing M. elsdenii NCIMB 41125 resulted in higher starter intake, which could have additionally stimulated reticulorumen development (Tamate et al., 1962; Kristensen et al., 2007) as a result of consuming greater volume of feed and higher nutrient intake (Gorka et al., 2011). Direct effects on gene expression within the rumen (Glauber et al., 1991), and an increase in blood flow through the rumen (Sander et al., 1959) are also suggested as mechanism by which butyrate may stimulate papillae development.

However, mechanisms regulating rumen development and nutrient accessibility for developing calf tissues need further investigation. The biochemistry of plasma BHBA and rumen butyrate, as well as mechanisms of rumen epithelial metabolic activities and induction of papillary development are not well defined. More scientific clarity on these mechanisms would improve understanding when predicting growth rates and management of dairy calves. The long-term 
effects of dosing $M$. elsdenii NCIMB 41125 on rumen microbial populations and gut development and animal performance are also pertinent areas of study

\section{Conclusion}

Dosing M. elsdenii NCIMB 41125 increased ruminal butyrate and plasma BHBA, improved starter DMI and rumen development suggesting increased epithelium metabolism and ketogenesis resulting in greater absorptive area and improved absorption of digestive end products. Nevertheless, biochemical and physiological feedback pathways and the long-term survival of M. elsdenii NCIMB 41125 in the rumen should be investigated as well as long-term effects on performance.

\section{Acknowledgment}

This research was supported by the Agricultural Research Council, Animal Production Institute, South Africa, which is gratefully acknowledged.

\section{References}

Aikman, P.C. 2008. Effect of administration of Megasphaera elsdenii NCIMB 41125 lactate utilizing bacteria in early lactation on the production, health and rumen environment of highly productive dairy cows fed a high concentrate diet. CEDAR Report n0. 260, University of Reading, UK. Pp, 1-100.

Aikman, P.C., Henning P.H., Horn, C.H. and Jones A.K. 2009. Effect of Megasphaera elsdenii NCIMB 41125 supplementation on rumen fermentation and pH in early lactation dairy cows. ADSA Conf., Abstract n0. 33064. 
Allison, M.J., 1978: Production of branched-chain volatile fatty acids by certain anaerobic bacteria. Applied and Environmental Microbiology 35, 872-877.

Anderson, K.L., Nagaraja, T.G., Morrill, J.L., Avery, T.B., Galitzer, S.J., Boyer, J.E., 1987: Ruminal microbial development in conventionally or early-weaned calves. Journal af Animal Science 64, 1215-1226

Augenlicht, L.H.; Anthony, G.M.; Church T.L., 1999: Short-chain fatty acid metabolism, apoptosis, and Apcinitiated tumorigenesis in the mouse gastrointestinal mucosa. Cancer Research 59, 6005-6009.

Baldwin, R.L., 1998: Use of Isolated Ruminal Epithelial Cells in the Study of Rumen Metabolism . Journal of. Nutrition 128, 2 293S-296S.

Baldwin, R.L.; McLeod, K. R.; Klotz, J. L.; Heitmann, R. N., 2004: Rumen Development, Intestinal Growth and Hepatic Metabolism In The Pre- and Postweaning Ruminant. Journal of Dairy Science 87 (E. Suppl.), E55-E65.

Beharka A.A.; Nagraja T.G.; Morrill J.L.; Kennedy G.A.; Klemm R.D., 1998: Effects of form of the diet on anatomical, microbial, and fermentative development of the rumen of neonatal calves. Journal of Dairy Science 81, 1946-1955.

Britton, R; Krehbill, C., 1993: Nutrient metabolism by gut tissue. Journal of Dairy Science 76, 2125-2135.

Broderick, G.A.; Kang, J.H., 1980: Automated simultaneuos determination of ammonia and total amino acids in rumen fluid and in vitro media. Journal of Dairy Science 63, 64-75.

Bush, R. S., 1988. Effect of age and diet on in vitro metabolism in rumen epithelium from Holstein calves. Canadian Journal of nimal Science 62, 429-438. 
Coverdale, J. A.; Tyler, H. D.; Quigle, J. D.; Brumm, J. A., 2004: Effect of various levels of forage and form of diet on rumen development and growth in calves. Journal of Dairy Science 87, 2554-2562.

Drouillard, J.S., 2004: Oral dosing of feedlot cattle with Megasphaera elsdenii: impact on adaptation to high concentrate diets. Research Report: Project no. 2003 - 12, Kansas State University, Manhattan.

Giesecke, D.; Wiesmayr, S.; Ledinek, M., 1970: Peptostreptococcus elsdenii. Canadian Journal of Microbiology 64, $123-126$

Glauber, J. G.; Wandersee, N. J.; Little, J. A.; Ginder, G. D., 1991: 5'-Flanking sequences mediate butyrate stimulation of embryonic globin gene expressioin in adult erythroid cells. Journal of Molecular Cell Biology 11, $4690-4697$.

Górka, P.; Kowalski, Z.M.; Pietrzak, P., Kotunia, A. Jagusiak, W.; Holst, J.J.; Guilloteau, P.; Zabielski, R., .2011: Effect of method of delivery of sodium butyrate on rumen development in newborn calves. Journal of Dairy Science 94, 5578-5588.

Greenwood, R.H.; Morrill, J.L.; Titgemeyer, E.C.; Kennedy, G.A., 1997: A new method of measuring diet abrasion and its effect on the development of the forestomach. Journal of Dairy Science 80, 2534-2541.

Hamada, T.; Maeda, S.; Kameoka, K., 1976: Factors influencing growth of rumen, liver, and other organs in kids weaned from milk replacers to solid foods. Journal of Dairy Science 59, 1110-1118.

Heerdt, B.G., Houston M.A., Augenlicht L.H. 1994. Potential by specific short chain fatty acids of differentiation and apoptosis in human colonic carcinoma cell lines. Cancer Res. 54:3288-3294.

Heinrichs, A.J. and K.E. Lesmeister. 2005. "Rumen Development in the Dairy Calf." Calf and Heifer Rearing. Nottingham: Nottingham University Press. Pp 53-65. 
Henning, P.H.; Campbell, A.A.; Hagg, F.M.; Horn, C.H., 2009. Effect of accelerated diet step-up rate on performance of feedlot steers dosed with Megasphaera elsdenii NCIMB 41125. In: Ruminant Physiology Digestion, Metabolism and Effects of Nutrition on Reproduction and Welfare. Eds Chilliard, Y., Glasser, F., Faulconnier, Y., Bocquier, Y., Veissier, I. \& Doreau, M., Wageningen Academic Publishers. pp. 78-79.

Henning, P.H.; Horn, C.H.; Steyn, D.G.; Meissner, H.H., 2010: The potential of Megasphaera elsdenii isolates to control ruminal acidosis. Animal. Feed Science and Technology 157, 13-19.

Kauffold, P.; Voigt, J.; Herrendorfer, G., 1977: Studies investigating the influence of nutritional factors on the ruminal mucosa. (3) State of the ruminal mucosa after infusions of propionic acid, acetic acid and butyric acid. Archives of Animal Nutrition 27, 201-211.

Khan, M.A.; Weary, D.M.; vn Keyserlingk, M.A.G., 2011: Hay intake improves performance and rumen development of calves fed higher quantity of milk. Journal of Dairy Science 94, 3547-3553.

Kristensen, N. B.; Sehested, J.; Jensen, S. K.; Vestergaard. M., 2007. Effect of milk allowance on concentrate intake, ruminal environment, and ruminal development in milk-fed Holstein calves. Journal of Dairy Science 90, $4346-4355$.

Lane, M.A.; Jesse, B.W., 1997: effect of volatile fatty acid infusion on development of the rumen epithelium in neonatal sheep. Journal of Dairy Science 80, 740-746.

Leeuw, K-J.; Siebrits, F.K.; Henning, P.H.; Meissner, H.H., 2009. Effect of Megasphaera elsdenii NCIMB 41125 drenching on health and performance of steers fed high and low roughage diets in the feedlot. S. Afr. Journal of Animal Science 39, 337-348. 
Lesmeister, K. E., Tozer, P. R.; Heinrichs, A. J., 2004: Development and Analysis of a Rumen Tissue Sampling Procedure. Journal of Dairy Science 87, 1336-1344.

Lesmeister, K.E.; Heinrichs, A.J., 2004: Effects of corn processing on growth characteristics, rumen development, and rumen parameters in neonatal dairy calves. Journal of Dairy Science 87, 3439-3450.

Marounek, M.; Fliegerova, K.; Bartos, S., 1989: Metabolism and some characteristics of ruminal strains of Megasphaera elsdenii. Applied and Environmental Microbiology 55, 1570 -1573.

Mentschel, J.; Leiser, R.; Mülling, C.; Pfarrer, C.; Claus, R., 2001: Butyric acid stimulates rumen mucosa development in the calf mainly by a reduction of apoptosis. Arch Tierenähr 55, 85-102.

Miller, K.A., Van Bibber-Kruegur, C.L.; Hollis, L.C.; Drouillard, J.S., 2013: Megasphaera elsdenii dosed orally at processing to reduce BRD and improve gain in high-risk calves during the receiving period. The bovine practitioner 47(2), 137-145.

Quigley, III, J. D.; Caldwell, L.A.; Sinks, G.D.; Heitmann, R.N., 1991: Changes in blood glucose, nonesterified fatty acids, and ketones in response to weaning and feed intake in young calves. Journal of Dairy Science 74, 250257.

Sander, E. G.; Warner, R. G.; Harrison, H. N.; Loosli, J. K., 1959: The stimulatory effect of sodium butyrate and sodium propionate on the development of rumen mucosa in the young calf. Journal of Dairy Science 42, 1600-1605.

Stewart, C.S.; Bryant, M. P., 1988: The rumen bacteria. in Hobson P.N. (eds), The rumen Microbial Ecosystem. Elsevier Applied Science. London-New York, pp. 21-76.

Stobo, I. J. F.; Roy, J. H. B.; Gaston, H. J., 1966: Rumen development in the calf. 1. The effect of diets containing different proportions of concentrates to hay on rumen development. British Journal of Nutrition 20, $171-188$. 
Tamate, H.; McGilliard, A. D.; Jacobson, N. L.; Getty, R., 1962: Effect of various dietaries on the anatomical development of the stomach in the calf. Journal of Dairy Science 45, 408-420.

Terré, M., Devant, M., Bach, A., 2007: Effect of level of milk replacer fed to Holstein calves on performance during the preweaning period and starter digestibility at weaning. Livestock Science 110: 82-88.

Wallace, R.J., 1986: Catabolism of amino acids by Megasphaera elsdenii. LC1. Applied and Environmental Microbiology 51, 1141-1143.

Warner, R. G.; Flatt, W. P.; Loosli. J. K., 1956. Dietary factors influencing the development of the animal's stomach. Journal of Agriculture and Food Chemistry 4, 788-792.

Weigand, E.; Young, J.W.; McGilliard. A.D., 1975. Volatile fatty acid metabolism by rumen mucosa from cattle fed hay or grain. Journal of Dairy Science 58, 1294-1300.

Zitnan, R.; Voigt, J.; Schönhusen, U.; Wegner, J.; Kokardova, M.; Hagemeister, H.; Levkut, M.; Kuhla, S.; Sommer, A., 1998: Influence of dietary concentrate to forage ratio on the development of rumen mucosa in calves. Archives of Animal Nutrition 51, 279-291. 